\title{
Effects of Marathon Running on Aerobic Fitness and Performance in Recreational Runners One Week after a Race
}

\author{
Fuminori Takayama, ${ }^{1,2}$ Atsushi Aoyagi, ${ }^{1}$ Wataru Shimazu, ${ }^{1}$ and Yoshiharu Nabekura ${ }^{3}$ \\ ${ }^{1}$ Graduate School of Comprehensive Human Sciences, University of Tsukuba, 1-1-1 Tennodai, Tsukuba, Ibaraki 305-8574, Japan \\ ${ }^{2} J a p a n$ Society for the Promotion of Sciences, 5-3-1 Kojimachi, Chiyoda-ku, Tokyo 102-0083, Japan \\ ${ }^{3}$ Faculty of Health and Sport Science, University of Tsukuba, 1-1-1 Tennodai, Tsukuba, Ibaraki 305-8574, Japan \\ Correspondence should be addressed to Yoshiharu Nabekura; nabekura.yoshihar.fm@u.tsukuba.ac.jp
}

Received 1 May 2017; Revised 10 July 2017; Accepted 20 July 2017; Published 24 August 2017

Academic Editor: Andrew Bosch

Copyright (C) 2017 Fuminori Takayama et al. This is an open access article distributed under the Creative Commons Attribution License, which permits unrestricted use, distribution, and reproduction in any medium, provided the original work is properly cited.

\begin{abstract}
It is not clear whether or not recreational runners can recover aerobic fitness and performance within one week after marathon running. This study aimed to investigate the effects of running a marathon race on aerobic fitness and performance one week later. Eleven recreational runners (six men, five women) completed the race in $3 \mathrm{~h} 36 \mathrm{~min} 20 \mathrm{~s} \pm 41 \mathrm{~min} 34 \mathrm{~s}$ (mean \pm standard deviation). Before and 7 days after the race, they performed a treadmill running test. Perceived muscle soreness was assessed before the race and for the following 7 days. The magnitude of changes in the treadmill running test was considered possibly trivial for maximal oxygen

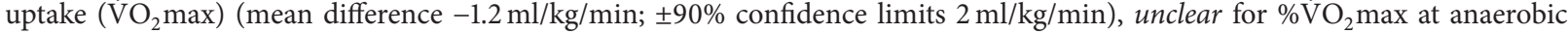
threshold (AT) $(-0.5 ; \pm 4.1 \%)$ and RE $(0.2 ; \pm 3.5 \mathrm{ml} / \mathrm{kg} / \mathrm{km})$, and likely trivial for both velocity at AT and peak $(-0.2 ; \pm 0.49 \mathrm{~km} / \mathrm{h}$ and $-0.3 ; \pm 0.28 \mathrm{~km} / \mathrm{h}$ ). Perceived muscle soreness increased until 3 days after the race, but there were no clear differences between the values before the race and 4-7 days after it. These results show that physiological capacity associated with marathon running performance is recovered within 7 days after a marathon run.
\end{abstract}

\section{Introduction}

Marathon running (running for $42 \mathrm{~km}$ ) is a popular form of vigorous physical activity [1]. Whatever the runner's level of ability, marathon running places an increased workload on their physiological function over the course of several hours. A previous study showed that during a marathon race the fractional use of maximal heart rate ranged from about $80 \%$ to $90 \%$ [2], suggesting that cardiorespiratory strain is high.

The number of recreational marathon runners has increased over the last decade [3]. Some runners participate in consecutive weekend races [4]. The high frequency of races that do not allow for sufficient recovery time may lead to causing overtraining syndrome. Overtraining has been defined as excessive stress without adequate rest or recovery period, which results in performance decrements with or without related change physiological sign [5].

Among the physiological characteristics, maximal oxygen uptake $\left(\dot{\mathrm{VO}}_{2} \max \right)$, fractional utilization of $\dot{\mathrm{VO}}_{2} \max$
(\% $\mathrm{VO}_{2}$ max, determined from anaerobic threshold: AT), and running economy (RE) have been used as the classic model of predicting distance running performance [6]. In addition to these measures of aerobic fitness, both velocity at AT and peak during a treadmill running test are used as indirect measurement of long distance running performance $[7,8]$. For example, Noakes et al. demonstrated a strong correlation between peak velocity and marathon time $(r=-0.89$, $p<0.01$ ) in marathon runners (range of race time: $2 \mathrm{~h} 08 \mathrm{~min}-3 \mathrm{~h} 26 \mathrm{~min}$ ) [7].

Recovery is typically quantified as ability to meet or exceed preexercise performance in a particular activity [9]. There is a relative lack of information on recovery of aerobic fitness and performance. Among the limited studies on this topic, Kyröläinen et al. investigated $\mathrm{V}_{2}$ during submaximal running before and for the 6 days after marathon running and reported that it took 4-6 days to recover to the condition before marathon running [10]. This result implied that 
TABLE 1: Physical characteristics and training status of the subjects.

\begin{tabular}{lc}
\hline & Mean \pm SD \\
\hline Age (years) & $24 \pm 4$ \\
Height $(\mathrm{cm})$ & $168 \pm 9$ \\
Weight $(\mathrm{kg})$ & $62.0 \pm 9.8$ \\
Running experience (years) & $6 \pm 4$ \\
Training distance during the 1 & $215 \pm 145$ \\
month before the race $(\mathrm{km})$ & \\
\hline
\end{tabular}

submaximal aerobic fitness could be recovered within one week after a race. For maximal aerobic fitness, Noble et al. showed no significant difference in $\dot{\mathrm{VO}}_{2}$ max between the value before the race and 2 weeks after it [11]. On the other hand, most recent evidence has indicated that peak oxygen uptake was significantly lower 3 to 4 days after a marathon than it was before the race, suggesting that marathon running reduces maximal aerobic fitness for the first few days after a race [12]. However, we are unaware of any studies that have tried simultaneously to elucidate the effects of marathon running on $\dot{\mathrm{V}} \mathrm{O}_{2} \max , \% \dot{\mathrm{V}} \mathrm{O}_{2} \max$, and $\mathrm{RE}$ after a race. Thus, it remains unclear whether or not a runner can completely recover aerobic fitness and performance within one week after marathon running. Marathon races are generally held every weekend, and it is therefore extremely important for recreational runners to understand recovery status a week after marathon running.

The purpose of the present study was to investigate the effects of marathon running on aerobic fitness and performance one week after a race. We hypothesized that marathon running would result in no differences in physiological characteristics a week after a race.

\section{Materials and Methods}

2.1. Participants. Eleven recreational runners (6 males, 5 females) participated in the study. The inclusion criteria were as follows: (1) the subjects regularly trained at least three days per week for a marathon race; (2) the subjects were healthy and reported no cardiorespiratory or musculoskeletal disorders; (3) the subjects were of an adult age; and (4) the subjects were nonsmokers. Before participation, the participants were provided with information sheets about the study process, and they provided written informed consent and completed a questionnaire regarding their training status. The physical characteristics and training status of the participants are shown in Table 1 . This study was approved by the Ethical Committee of the University of Tsukuba (Ref number Tai 27-76).

2.2. Experimental Design. All measurements were made before and after the Tsukuba Marathon held in Ibaraki, Japan. To increase sample size, the present study was conducted over a 2-year period. Eight subjects participated in the race 2015 and three subjects participated in the race 2016. The race was officially recognized by the Japan Association of Athletics Federations and a flat-road race course. Both races were cloudy and had similar conditions: the temperature was $12.4^{\circ} \mathrm{C}$ and $10.1^{\circ} \mathrm{C}$, the relative humidity $68 \%$ and $98 \%$, and wind speed $2.5 \mathrm{~m} / \mathrm{s}$ and $2.0 \mathrm{~m} / \mathrm{s}$, respectively, at the start of the race.

To investigate the effects of marathon running on physiological characteristics one week after the race, a treadmill running test was performed 1-2 weeks before (PRE) and 7 days after (POST) the marathon by the same investigators. Individual tests were performed at the same time of day $( \pm 1 \mathrm{~h})$ to avoid any diurnal variation effects. In addition, perceived muscle soreness was recorded before and for the 7 days after the race.

2.3. Treadmill Running Test. The subjects were familiarized with treadmill running before the PRE measurement. The test was performed on a motorized treadmill (ORK-7000, Ohtake Root Kogyo, Japan) set at $1 \%$ grade, which accurately reflects the energetic cost of outdoor running [13]. The subjects consumed a light meal at least $3 \mathrm{~h}$ before the test, and during the $3 \mathrm{~h}$ preceding the test only ad libitum water intake was allowed. Body weight was measured before the test (TBF-102, Tanita, Japan).

The subjects completed a two-part test that consisted of RE test and a maximal incremental test. Expired gas analysis was continuously performed on a breath-by-breath basis using the computerized standard open circuit technique, and the data were then converted into 20-s time binned mean values (AE-310s, Minato Medical Science, Japan). Before each test, the oxygen and carbon dioxide analysers were calibrated using known gas concentrations and flow calibration was performed using a 2-L syringe. HR was collected via telemetry (Polar, Finland).

The subjects underwent a 5-min RE test at submaximal intensity. The intensity was set for each subject based on their questionnaire answer about their target time for the race. As $\mathrm{RE}$ can be assessed by $\mathrm{VO}_{2}$ in steady state submaximal running [14], we set the treadmill velocity at $85 \%$ of the velocity corresponding with the target time of the race. The gas analysis data during the last 1-min were used in the analysis. $\mathrm{RE}$ was expressed as $\mathrm{O}_{2}$ cost $(\mathrm{ml} / \mathrm{kg} / \mathrm{km})$.

Following a 5-min recovery period after the RE test, the maximal incremental test was performed to determine $\dot{\mathrm{VO}}_{2} \max , \mathrm{AT}$, and peak velocity. The initial velocity was set at $8.4 \mathrm{~km} / \mathrm{h}$ and it was increased by $0.6 \mathrm{~km} / \mathrm{h}$ every $60 \mathrm{~s}$ until volitional exhaustion, defined as the point at which the subject could no longer run at the required velocity. The subjects were always verbally encouraged by the same investigators. To avoid external feedback, the subjects were unable to see the displays of the expired gas analysis and heart rate. AT was defined as the point when respiratory exchange ratio (RER) stabilized above 1.0 not returning to levels below [15]. The AT was expressed as velocity and $\% \dot{\mathrm{VO}_{2}} \max \left(\% \dot{\mathrm{VO}}_{2} \max\right.$ at $\left.\mathrm{AT}\right)$. $\mathrm{VO}_{2}$ max was defined by the attainment of at least three of the following four criteria: (1) a leveling off in $\mathrm{VO}_{2}$ despite an increase in a treadmill velocity, (2) RER $\geq 1.1$, (3) HR $\geq 90 \%$ of the subject's age-predicted HRmax (i.e., 220 - age), and (4) peak RPE $\geq 19$. Peak velocity was determined by the last stage of the test. When the subject was unable to complete a full $60 \mathrm{~s}$ at the required velocity, the 
TABLE 2: Changes in aerobic fitness before and seven days after a marathon race.

\begin{tabular}{|c|c|c|c|c|c|c|}
\hline & PRE & POST & $p$ value & Mean difference; 90\% CL & Effect size & Qualitative inference \\
\hline $\mathrm{O}_{2} \operatorname{cost}(\mathrm{ml} / \mathrm{kg} / \mathrm{km})$ & $221.0 \pm 14.9$ & $221.2 \pm 11.2$ & 0.919 & $0.2 ; \pm 3.5$ & 0.02 & Unclear \\
\hline$\% \dot{\mathrm{V}} \mathrm{O}_{2} \max$ at $\mathrm{AT}(\%)$ & $85.8 \pm 4.7$ & $85.3 \pm 4.6$ & 0.830 & $-0.5 ; \pm 4.1$ & -0.10 & Unclear \\
\hline$\dot{\mathrm{VO}}_{2} \max (\mathrm{ml} / \mathrm{kg} / \mathrm{min})$ & $59.3 \pm 9.5$ & $58.1 \pm 9.2$ & 0.294 & $-1.2 ; \pm 2$ & -0.12 & Possibly trivial \\
\hline $\mathrm{AT}(\mathrm{km} / \mathrm{h})$ & $14.6 \pm 2.6$ & $14.4 \pm 2.3$ & 0.476 & $-0.2 ; \pm 0.49$ & -0.09 & Likely trivial \\
\hline Peak velocity $(\mathrm{km} / \mathrm{h})$ & $17.2 \pm 2.5$ & $16.9 \pm 2.5$ & 0.082 & $-0.3 ; \pm 0.28$ & -0.09 & Likely trivial \\
\hline
\end{tabular}

peak velocity was determined as a fraction of the final velocity added to the velocity in the immediately preceding $60 \mathrm{~s}$.

2.4. Perceived Muscle Soreness. Perceived muscle soreness was assessed using a verbal rating scale of 0 (no pain) to 10 (extreme pain) [16]. Before and 7 days after running the marathon, perceived muscle soreness was determined before undertaking the treadmill running test, whereas it was assessed every evening for the 6 days after the marathon. The subjects were instructed to record the soreness levels of their knee extensors, knee flexors, plantar flexors, hips, upper back, lower back, shoulders, elbow flexors, and elbow extensors on a questionnaire sheet while stretching specific muscles.

2.5. Statistical Analysis. The statistical analyses were performed with SPSS Statistics 22 (IBM Japan, Japan). Data are expressed as mean and SD. Because recovery is typically quantified as the ability to meet or exceed preexercise performance in a particular activity [9], we conducted paired $t$-tests to estimate the post-pre difference in outcomes. Perceived muscle soreness was analyzed by separate oneway repeated-measures analyses of variance (ANOVAs) and Dunnett post hoc tests. Assumptions of sphericity were assessed using Mauchly's test, with any violations adjusted via the Greenhouse-Geisser correction. The data were analyzed for practical significance using Cohens' $d$ effect sizes (ES) and magnitude-based inferences. The ES were classified as trivial $(<0.2)$, small $(0.2-0.6)$, moderate $(0.6-1.2)$, large $(1.2-2.0)$, and very large $(>2.0)$ [17]. Ninety percent confidence intervals for between PRE and POST differences in changes were estimated, and magnitude-based inferences were made with reference to the smallest worthwhile change (SWC), which was calculated as being 0.2 between-subject standard deviation of the PRE value. Quantitative chances of higher or lower differences than SWC were evaluated qualitatively as follows: $<0.5 \%$, most unlikely or almost certainly not; $0.5 \%$ to $5 \%$, very unlikely; $5 \%$ to $25 \%$, unlikely or probably not; $25 \%$ to $75 \%$, possibly; $75 \%$ to $95 \%$, likely or probably; $95 \%$ to $99.5 \%$, very likely; $>99.5 \%$, most likely or almost certainly. If the chance of an increase and decrease effect were both $>5 \%$, the true difference was considered to be unclear [17].

Relationships between both velocity at AT and peak and the average velocity during the marathon were determined using Pearson's product-moment correlation coefficient tests. Simultaneous multiple regression analysis was used to predict performance from a classic model that included $\dot{\mathrm{V}}_{2} \max$, $\% \dot{\mathrm{VO}}_{2}$ max at $\mathrm{AT}$, and RE.

\section{Results}

The subjects completed the race in $3 \mathrm{~h} 36 \mathrm{~min} 20 \mathrm{~s} \pm$ $41 \mathrm{~min} 34 \mathrm{~s}$ (range: $2 \mathrm{~h} 31 \mathrm{~min} 22 \mathrm{~s}$ to $4 \mathrm{~h} 54 \mathrm{~min} 48 \mathrm{~s}$ ), which is similar to the combined target time for the race $(3 \mathrm{~h} 37 \mathrm{~min} 38 \mathrm{~s} \pm 54 \mathrm{~min} 02 \mathrm{~s}, p>0.05)$. The subjects' average velocity during the marathon was $12.1 \pm 2.4 \mathrm{~km} / \mathrm{h}$.

3.1. Treadmill Running Test. Table 2 shows the changes in aerobic fitness and indirect performance from PRE to POST. The mean velocity in the RE test was $10.5 \pm 2.6 \mathrm{~km} / \mathrm{h}$. In the RE test, the RER of all subjects were less than 1.00, both PRE and POST. For all three variables, no significant differences or trivial effect sizes were observed between values measured PRE and POST. The magnitude of changes was considered possibly trivial for $\dot{\mathrm{VO}}_{2} \max$, unclear for $\% \mathrm{~V}_{2} \max$ and $\mathrm{RE}$, and likely trivial for both velocity at AT and peak. Significant correlations were found between the subject's average velocity during the marathon and PRE values of AT $(\mathrm{km} / \mathrm{h})(r=$ 0.899; $p<0.001)$ and peak velocity $(r=0.916 ; p<$ 0.001). Similarly, the average velocity during the marathon was significantly correlated with the POST values of AT $(r=0.897 ; p<0.001)$ and peak velocity $(r=0.907$; $p<0.001)$. Simultaneous multiple regression analysis was used to determine whether the classic model could predict average velocity during the marathon. A significant prediction equation was found $(F=15.363, p=0.002)$ that accounted for $87 \%$ of the variance in average velocity during the marathon $\left(R^{2}=0.87\right)$ at PRE measurement. In the same way, a significant prediction was found $(F=12.450, p=0.003)$ that accounted for $84 \%$ of the variance in average velocity during the marathon $\left(R^{2}=0.84\right)$ at POST measurement.

3.2. Perceived Muscle Soreness. Table 3 shows the changes in perceived muscle soreness. Separate one-way ANOVAs demonstrated significant main effects of day for the perceived muscle soreness of all muscles. The increases in knee extensors were most likely at 1 and 2 days after the marathon and very likely at 3 days. The increases in knee flexors and hips were most likely at 1 and 2 days after the marathon. The increases in plantar flexors, upper back, and lower back were most likely at 1 day after the marathon and very likely at 2 days after. The increases in shoulders were most likely at 1 day after the marathon and likely at 2 days after. The increases in elbow flexors were likely at 1 day after the marathon. However, there 
TABLE 3: Perceived muscle soreness before and for seven days after a marathon race.

\begin{tabular}{|c|c|c|c|c|c|c|c|c|}
\hline & Before & 1 day & 2 days & 3 days & 4 days & 5 days & 6 days & 7 days \\
\hline Knee extensors & $1.0 \pm 1.3$ & $6.1 \pm 2.2^{* * * *}$ & $4.8 \pm 2.2^{* * * *}$ & $2.8 \pm 1.9^{* * *}$ & $1.9 \pm 1.2$ & $1.1 \pm 0.9$ & $1.2 \pm 1.1$ & $0.7 \pm 1.1$ \\
\hline Knee flexors & $1.4 \pm 1.2$ & $5.2 \pm 2.4^{* * * *}$ & $4.0 \pm 2.2^{* * * *}$ & $2.5 \pm 1.8$ & $1.5 \pm 1.1$ & $1.2 \pm 1.1$ & $1.3 \pm 1.0$ & $0.7 \pm 1.1$ \\
\hline Plantar flexors & $1.7 \pm 2.2$ & $4.9 \pm 2.0^{* * * *}$ & $3.5 \pm 2.1^{* * *}$ & $1.9 \pm 1.5$ & $1.4 \pm 1.3$ & $1.3 \pm 1.1$ & $1.2 \pm 1.0$ & $0.6 \pm 1.0$ \\
\hline Hips & $0.9 \pm 1.4$ & $4.0 \pm 2.9^{* * * *}$ & $2.9 \pm 2.3^{* * * *}$ & $1.6 \pm 1.4$ & $1.3 \pm 1.3$ & $1.2 \pm 1.5$ & $1.1 \pm 1.1$ & $0.9 \pm 1.3$ \\
\hline Upper back & $0.5 \pm 0.8$ & $1.8 \pm 1.9^{* * * *}$ & $1.5 \pm 1.4^{* * *}$ & $0.5 \pm 0.8$ & $0.4 \pm 0.7$ & $0.3 \pm 0.6$ & $0.5 \pm 1.0$ & $0.3 \pm 0.6$ \\
\hline Lower back & $0.7 \pm 1.0$ & $2.6 \pm 2.6^{* * * *}$ & $2.0 \pm 2.2^{* * *}$ & $1.2 \pm 2.0$ & $0.8 \pm 1.8$ & $0.7 \pm 1.7$ & $0.6 \pm 1.2$ & $0.5 \pm 0.8$ \\
\hline Shoulders & $0.9 \pm 1.6$ & $2.8 \pm 2.6^{* * * *}$ & $1.9 \pm 2.0^{* *}$ & $0.8 \pm 1.0$ & $0.5 \pm 0.8$ & $0.5 \pm 0.8$ & $0.6 \pm 1.1$ & $0.5 \pm 0.8$ \\
\hline Elbow flexors & $0.7 \pm 1.6$ & $1.8 \pm 1.8^{* *}$ & $0.8 \pm 1.3$ & $0.5 \pm 0.8$ & $0.3 \pm 0.6$ & $0.1 \pm 0.3$ & $0.2 \pm 0.4$ & $0.1 \pm 0.3$ \\
\hline Elbow extensors & $0.6 \pm 1.6$ & $1.2 \pm 1.7$ & $0.5 \pm 1.0$ & $0.2 \pm 0.6$ & $0.2 \pm 0.6$ & $0.1 \pm 0.3$ & $0.1 \pm 0.3$ & $0.2 \pm 0.6$ \\
\hline
\end{tabular}

Qualified likelihood was shown as increased number of symbols: ${ }^{*}$ possible, ${ }^{* *}$ likely, ${ }^{* * *}$ very likely, and ${ }^{* * * *}$ most likely.

were no clear differences in any variables between before and 4-7 days after the marathon.

\section{Discussion}

The main determinants of marathon running performance are aerobic fitness [6]. Previous study has shown that classic model $\left(\dot{\mathrm{VO}}_{2} \max , \% \dot{\mathrm{VO}}_{2} \max\right.$, and $\mathrm{RE}$ ) explains $>70 \%$ of variance in distance running performance [18]. In the present study, classic model explained more than $80 \%$ of variance in average velocity during marathon. Moreover, the significant relationships between performance variables and marathon performance were similar to those reported in previous study [7]. Thus, the treadmill running test used in the present study was an effective method for predicting marathon running performance.

To the best of our knowledge, the present study is the first to systematically investigate the effects of marathon running on aerobic fitness one week after a marathon race. We found no significant differences between the values of $\dot{\mathrm{VO}}_{2} \max , \% \dot{\mathrm{VO}}_{2}$ max at $\mathrm{AT}$, and $\mathrm{RE}$ measured before and 7 days after completing a marathon. Moreover, the results of magnitude-based inferences showed that marathon running does not have an adverse effect on aerobic fitness and performance seven days after the race. As mentioned earlier, recovery is typically quantified as ability to meet or exceed preexercise performance in a particular activity [9]. Based on the results of the present study, the examined physiological characteristics related to marathon running performance can recover within one week after running a marathon in a sample of recreational runners.

It is well known that marathon running induces delayedonset muscle soreness (DOMS) $[19,20]$, which is one of the main symptoms of exercise induced muscle damage (EIMD). Not only is DOMS an indication of subclinical injury [21] but it also has a negative impact on aerobic fitness [22, 23] and performance [24] during running. For example, Braun and Dutto investigated changes in $\dot{\mathrm{VO}}_{2}$ during steady state submaximal running and muscle soreness before and 2 days after downhill running and showed that $\dot{\mathrm{VO}}_{2}$ and muscle soreness were significantly elevated 2 days after the exercise [23]. Based on this result, they noted changes in RE due to downhill running-induced muscle damage. Another study has also reported that peak oxygen uptake and velocity at ventilatory threshold were reduced and perceived muscle soreness increased 7 days after single-leg split squats with $40 \%$ of body weight [22]. In comparison with the previous study [22], the magnitude of changes in physiological characteristics and perceived muscle soreness was milder in the present study. Although we did not measure other muscle damage markers such as creatine kinase activity and maximal voluntary isometric contraction torque, it has clearly been demonstrated in many studies that muscle damage markers can recover within one week after marathon running $[10,19$, 20, 25]. Taken together, we conclude that no differences in aerobic fitness and distance running performance result from the recovery from EIMD within one week after running a marathon.

There were some limitations to the present study. First, the study was descriptive and neither the training nor the food intake after marathon running was controlled. Previous studies suggested that some recovery methods, such as low intensity running [26] and the ingestion of branched-chain amino acids [27] and tart cherry juice [28], have an impact on the recovery of muscle damage after marathon running. Therefore, the varying activities performed by each individual after the race may have introduced some bias into the study results. Second, our sample was relatively small and of mixedsex. However, the treadmill running test is highly reliable for detecting small changes [29]. Moreover, both men and women have been shown to respond similarly to EIMD [30]. Third, it should be noted that the present study included only recreational runners and had no corresponding control group. Finally, we performed the treadmill running test only once after the subject had run a marathon. Further studies of the time course of recovery of physiological characteristics are needed to fully establish the recovery status after marathon running in runners with various levels of running ability such as elite runners.

\section{Conclusion}

In conclusion, this study estimated the effects of marathon running on aerobic fitness and performance one week after a marathon race. The results suggest that marathon running 
does not adversely affect a person's aerobic fitness and performance 7 days after the race. Based on the results of this study, we suggest that maximal aerobic performance capability and measure of threshold and economy are restored within one week after running a marathon.

\section{Conflicts of Interest}

The authors declare that they have no conflicts of interest.

\section{Acknowledgments}

This work was supported by the research grant from Japanese Society for Running.

\section{References}

[1] L. D. Sanchez, B. Corwell, and D. Berkoff, "Medical problems of marathon runners," American Journal of Emergency Medicine, vol. 24, no. 5, pp. 608-615, 2006.

[2] V. L. Billat, H. Petot, M. Landrain, R. Meilland, J. P. Koralsztein, and L. Mille-Hamard, "Cardiac output and performance during a marathon race in middle-aged recreational runners," The Scientific World Journal, vol. 2012, Article ID 810859, pp. 1-9, 2012.

[3] Running USA, "2015 running USA annual marathon report," May 2016, http://www.runningusa.org/marathon-report-2016.

[4] J. Davis, "The scientific research on how to prepare yourself to run back-to-back Marathons," https://runnersconnect.net/ back-to-back-marathons/.

[5] H. Kuipers and H. A. Keizer, "Overtraining in elite athletes: review and directions for the future," Sports Medicine, vol. 6, no. 2, pp. 79-92, 1988.

[6] M. J. Joyner, "Modeling: optimal marathon performance on the basis of physiological factors," Journal of Applied Physiology, vol. 70, no. 2, pp. 683-687, 1991.

[7] T. D. Noakes, K. H. Myburgh, and R. Schall, "Peak treadmill running velocity during the $\mathrm{VO}_{2}$ max test predicts running performance," Journal of Sports Sciences, vol. 8, no. 1, pp. 35-45, 1990.

[8] L. I. Tjelta and A. R. Tjelta, "Relationship between velocity at anaerobic threshold and factors affecting velocity at anaerobic threshold in elite distance runners," International Journal of Applied Sports Sciences, vol. 24, no. 1, pp. 8-17, 2012.

[9] P. A. Bishop, E. Jones, and A. K. Woods, "Recovery from training: a brief review," Journal of Strength and Conditioning Research, vol. 22, no. 3, pp. 1015-1024, 2008.

[10] H. Kyröläinen, T. Pullinen, R. Candau, J. Avela, P. Huttunen, and P. V. Komi, "Effects of marathon running on running economy and kinematics," European Journal of Applied Physiology, vol. 82, no. 4, pp. 297-304, 2000.

[11] B. J. Noble, C. M. Maresh, T. G. Allison, and A. Drash, "Cardiorespiratory and perceptual recovery from a marathon run," Medicine and Science in Sports and Exercise, vol. 11, no. 3, pp. 239-243, 1979.

[12] A. P. R. Sierra, A. D. da Silveira, R. C. Francisco et al., "Reduction in post-marathon peak oxygen consumption: Sign of cardiac fatigue in amateur runners?" Arquivos Brasileiros de Cardiologia, vol. 106, no. 2, pp. 92-96, 2016.
[13] A. M. Jones and J. H. Doust, "A $1 \%$ treadmill grade most accurately reflects the energetic cost of outdoor running," Journal of Sports Sciences, vol. 14, no. 4, pp. 321-327, 1996.

[14] P. U. Saunders, D. B. Pyne, R. D. Telford, and J. A. Hawley, "Factors affecting running economy in trained distance runners," Sports Medicine, vol. 34, no. 7, pp. 465-485, 2004.

[15] G. Solberg, B. Robstad, O. H. Skjønsberg, and F. Borchsenius, "Respiratory gas exchange indices for estimating the anaerobic threshold," Journal of Sports Science and Medicine, vol. 4, no. 1, pp. 29-36, 2005.

[16] K. Suzuki, J. Peake, K. Nosaka et al., "Changes in markers of muscle damage, inflammation and HSP70 after an Ironman triathlon race," European Journal of Applied Physiology, vol. 98, no. 6, pp. 525-534, 2006.

[17] W. G. Hopkins, S. W. Marshall, A. M. Batterham, and J. Hanin, "Progressive statistics for studies in sports medicine and exercise science," Medicine and Science in Sports and Exercise, vol. 41, no. 1, pp. 3-12, 2009.

[18] P. E. di Prampero, G. Atchou, J.-C. Brückner, and C. Moia, "The energetics of endurance running," European Journal of Applied Physiology and Occupational Physiology, vol. 55, no. 3, pp. 259266, 1986.

[19] J. A. Hill, G. Howatson, K. A. Van Someren, I. Walshe, and C. R. Pedlar, "Influence of compression garments on recovery after marathon running," Journal of Strength and Conditioning Research, vol. 28, no. 8, pp. 2228-2235, 2014.

[20] M. Tojima, K. Noma, and S. Torii, "Changes in serum creatine kinase, leg muscle tightness, and delayed onset muscle soreness after a full marathon race," Journal of Sports Medicine and Physical Fitness, vol. 56, no. 6, pp. 782-788, 2016.

[21] K. Cheung, P. A. Hume, and L. Maxwell, "Delayed onset muscle soreness: treatment strategies and performance factors," Sports Medicine, vol. 33, no. 2, pp. 145-164, 2003.

[22] C. D. Black, A. R. Gonglach, R. E. Hight, and J. B. Renfroe, "Time-course of recovery of peak oxygen uptake after exerciseinduced muscle damage," Respiratory Physiology and Neurobiology, vol. 216, pp. 70-77, 2015.

[23] W. A. Braun and D. J. Dutto, "The effects of a single bout of downhill running and ensuing delayed onset of muscle soreness on running economy performed $48 \mathrm{~h}$ later," European Journal of Applied Physiology, vol. 90, no. 1-2, pp. 29-34, 2003.

[24] S. M. Marcora and A. Bosio, "Effect of exercise-induced muscle damage on endurance running performance in humans," Scandinavian Journal of Medicine and Science in Sports, vol. 17, no. 6, pp. 662-671, 2007.

[25] Y. Kobayashi, T. Takeuchi, T. Hosoi, H. Yoshizaki, and J. A. Loeppky, "Effect of a marathon run on serum lipoproteins, creatine kinase, and lactate dehydrogenase in recreational runners," Research Quarterly for Exercise and Sport, vol. 76, no. 4, pp. 450-455, 2005.

[26] W. M. Sherman, L. E. Armstrong, T. E. Murray et al., "Effect of a 42.2-km footrace and subsequent rest or exercise on muscular strength and work capacity," Journal of Applied Physiology: Respiratory, Environmental and Exercise Physiology, vol. 57, no. 6, pp. 1668-1673, 1984.

[27] K. Ishikura, T. Miyazaki, RA. Song-Gyu, and H. Ohmori, “The ameliorating effect of branched-chain amino acids ingestion on different types of muscle soreness after swimming and fullmarathon running," Advances in Exercise and Sports Physiology, vol. 20, no. 1, p. 17, 2014.

[28] G. Howatson, M. P. McHugh, J. A. Hill et al., "Influence of tart cherry juice on indices of recovery following marathon 
running," Scandinavian Journal of Medicine and Science in Sports, vol. 20, no. 6, pp. 843-852, 2010.

[29] T. F. Lourenço, L. E. B. Martins, L. S. Tessutti, R. Brenzikofer, and D. V. MacEdo, "Reproducibility of an incremental treadmill $\mathrm{VO}_{2}$ max test with gas exchange analysis for runners," Journal of Strength and Conditioning Research, vol. 25, no. 7, pp. 1994-1999, 2011.

[30] J. Rinard, P. M. Clarkson, L. L. Smith, and M. Grossman, "Response of males and females to high-force eccentric exercise," Journal of Sports Sciences, vol. 18, no. 4, pp. 229-236, 2000. 


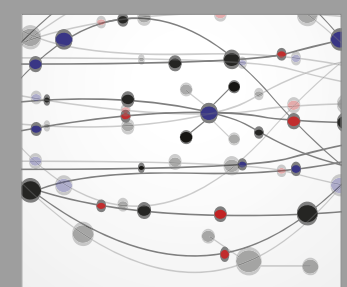

The Scientific World Journal
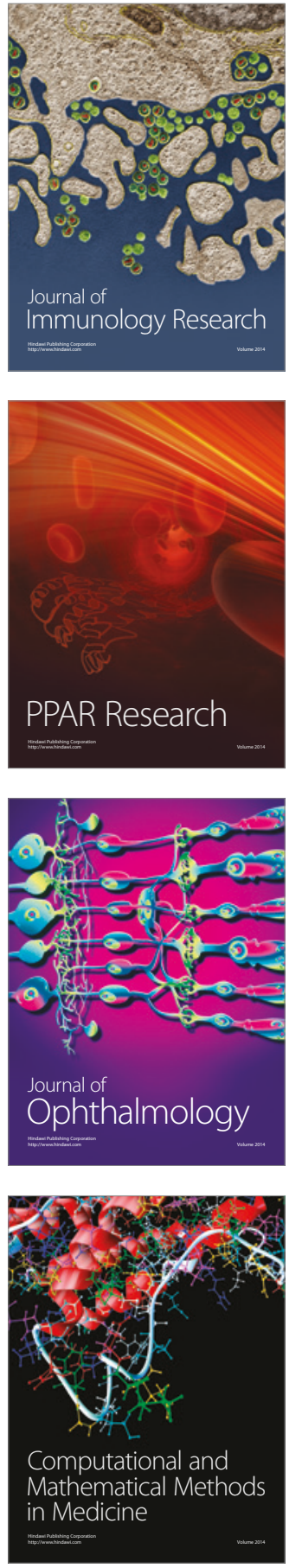

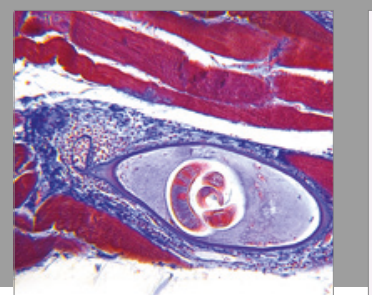

Gastroenterology Research and Practice
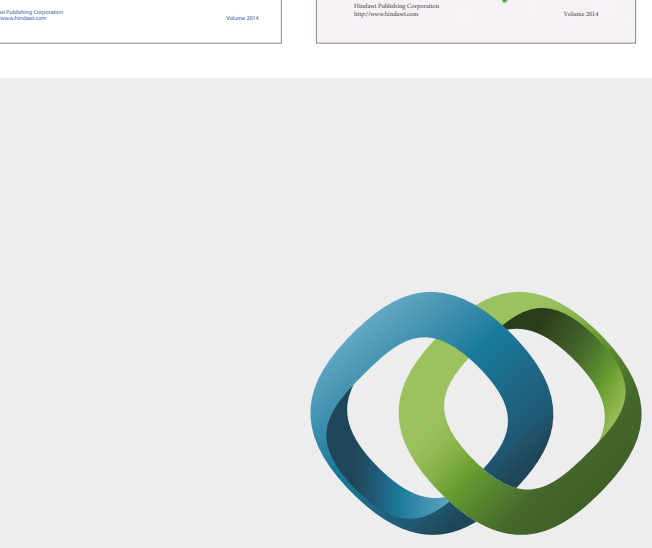

\section{Hindawi}

Submit your manuscripts at

https://www.hindawi.com
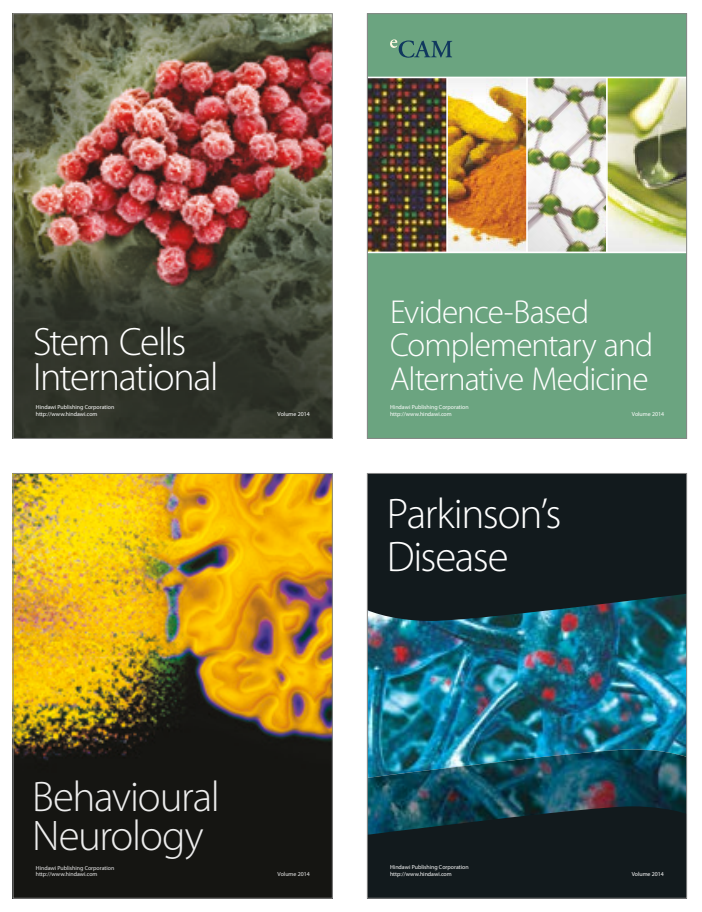
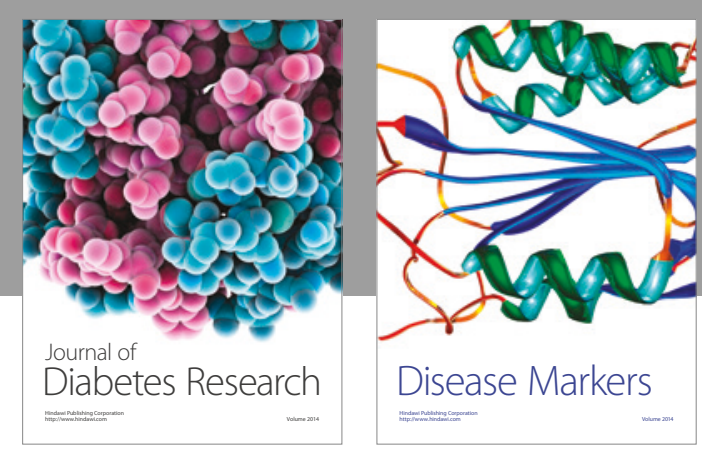

Disease Markers
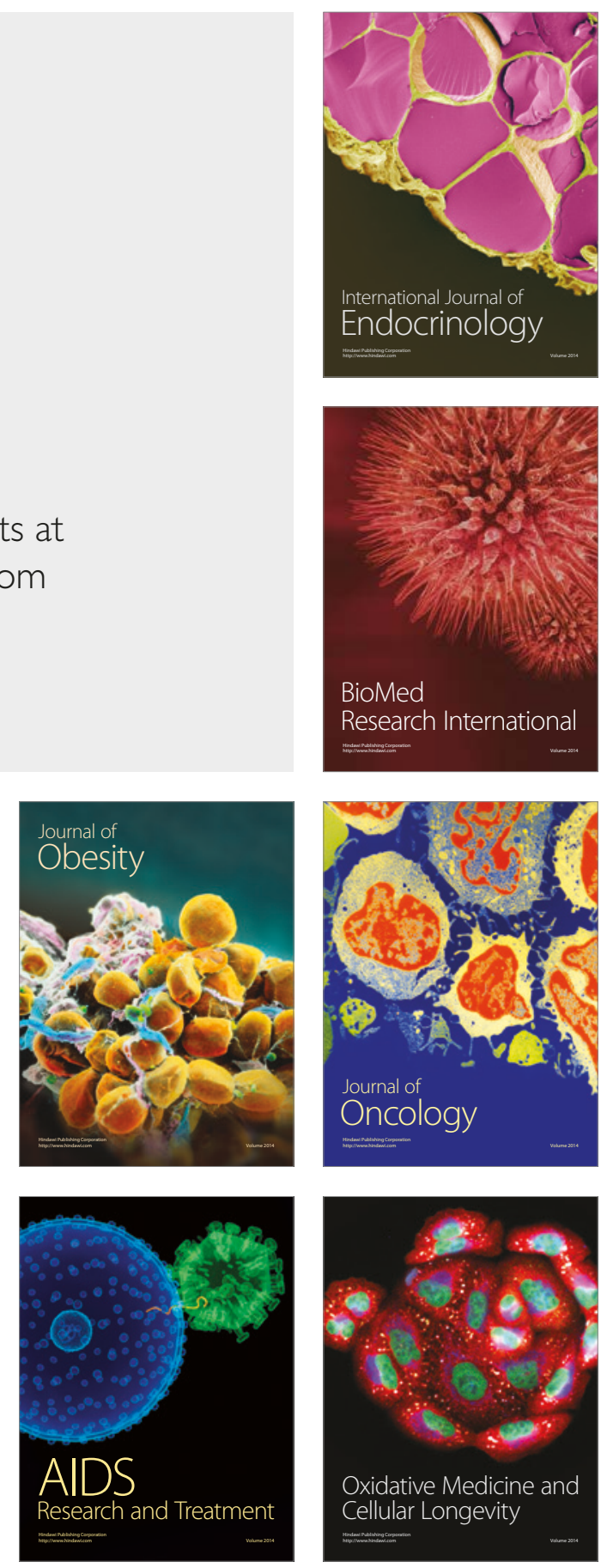